\title{
Pereira, Elenita M., Fabiano Q. Rückert, Neli G. Machado (eds.) História ambiental no Rio Grande do Sul. Lajeado: Editora da Univates, 2014. 224p.
}

Cyanna Missaglia de Fochesatto

Universidad do Vale do Rio dos Sinos, Unisinos

Bolsista CAPES/Prosup

cyanna.mf@gmail.com

Novo Hamburgo

Brasil

O livro "História Ambiental no Rio Grande do Sul", pioneiro em publicação oriunda do Grupo de Trabalho de História Ambiental da Associação Nacional de História (ANPUH-Rio Grande do Sul), aborda questões relacionadas à História Ambiental e suas tensões sociais, em um recorte temporal que remonta ao século XIX e XX, no Rio Grande do Sul. O livro é organizado pelos professores e fundadores do GT de História Ambiental no Rio Grande do Sul, Elenita Malta Pereira e Fabiano Quadros Rückert, ambos possuem uma significativa produção na área da pesquisa ambiental, e vêm promovendo debates e divulgando pesquisas consistentes e críticas em História Ambiental. Organizada também por Neli Teresinha Galarce Machado, professora e pesquisadora na área da Arqueologia, e que vem trabalhando em diálogo com a História Ambiental e Arqueologia da Paisagem. O livro encontra-se dividido em três linhas temáticas distintas: Cidade e Rios; Florestas, Migrações e Ruralidades; Arqueologia e Viajantes.

Na primeira linha temática, Cidade e Rios, são apresentados três artigos. No primeiro, elaborados pelos professores Fabiano Quadros Rückert e Marluza Marques Harres, são explorados os aspectos ambientais em São Leopoldo, sendo foco a relação dos banhados do Rio dos Sinos com a parte da sociedade mais pobre do município, no início do século XX. A poluição das águas do Rio dos Sinos é um dos personagens principais dessa narrativa, bém como a interação da natureza com o homem, através da mobilização social em prol da preservação das águas. A pesquisa parte de um rico apanhado de fontes, como jornais e documentos do governo, atas e relatórios do município. O estudo das águas se faz mais atual do que nunca, e, é mostrada a forma como a sociedade foi estruturando-se e crescendo em volta do Rio, marcando sua importância não apenas para a formação da colônia de São Leopoldo, mas para todo o processo de urbanização, no decorrer do século $X X$, e que vai culminar com as enchentes. Nessa relação das águas com a sociedade, são as famílias mais pobres as mais atingidas, pois são elas que vão se assentar nos banhados, ficando expostas às áreas de riscos 'e à precariedade de suas condições. O embate do homem com a natureza necessita de intermediadores que surgem nas figuras do poder público e dos movimentos ambientalistas, despertando uma preocupação humanitária e assistencialista quanto aos problemas das águas e de segurança dessas famílias, no município de São Leopoldo.

No artigo seguinte, Bread Soares Estevam e Elenita Malta Pereira tratam das lutas ambientais em Rio Grande, tendo como fonte principal os periódicos, especificamente o 
jornal Agora, de Rio Grande, partindo da análise das falas do ambientalista Luis Felipe Pinheiro Guerra. Em um contexto de desenvolvimento do porto de Rio Grande e criação de grandes polos petroquímicos, de crescente urbanização, consequências da expansão do capitalismo, teve início um vasto processo de poluição das águas e desequilíbrio da flora e da fauna ambiental, em meio ao um regime político autoritário. Nas crônicas ecológicas de Luiz Felipe Pinheiro Guerra, membro da AGAPAN/Rio Grande, foi traçado um perfil que mostra como ele teria se utilizado de diversas estratégias para denunciar as agressões a natureza, principalmente quanto às águas de Rio Grande, contaminadas pelo descarte de resíduos químicos e industriais. Para além da crítica ambiental, Guerra, como referência na luta pelo meio ambiente em Rio Grande, propôs alternativas para a preservação do mesmo, o que propiciaria um ambiente saudável a população, além de estimular o turismo.

O terceiro e último artigo da primeira parte do livro, escrito por Antonio João Dias Prestes, discute a poluição nas águas do Guaíba e suas praias, em Porto Alegre, nos anos 1960 e 1970. Foram mapeadas questões ecológicas e urbanas que permearam a degradação do Lago Guaíba. O despejo dos esgotos sem tratamento no Lago foi um dos maiores motivos da degradação do mesmo, e causou, posteriormente, a interdição do Lago para banho. Com a entrada do DMAE no cenário porto-alegrense, ocorreram tentativas de ampliar as localidades abastecidas e tratadas, mas isso acabou acarretando também ao aumento do material de descarte sem tratamento, agregando uma maior poluição para a cidade. A relação da sociedade com o caso da poluição das águas, nesse caso, seria de desinteresse. A população não teria se mobilizado quanto à poluição de forma efetiva, nem com o fechamento das praias nos anos 70; o caso que mais teria trazido transtornos para a sociedade teria sido a fábrica da Borregaard - devido aos gases malcheirosos que infestavam a cidade. Ainda que alguns ativistas tenham tomado a frente das manifestações contra a poluição das águas, a imprensa local teria dado maior ênfase para a inauguração da freeway.

A segunda parte do livro, intitulada Florestas, Migrações e Ruralidades, inicia-se com um artigo de Juliana Bublitz, tratando do processo de colonização alemão no Rio Grande do Sul, e partindo da ideia de uma fronteira verde, a qual os imigrantes que vieram tentar a sorte em solo gaúcho foram desafiados a enfrentar. A floresta foi vista como a inimiga a quem era necessário vencer e subjugar, uma vez que a terra brasileira possuía também a função de elevar o status do imigrante. A autora utilizou como fontes os diários dos viajantes e os relatos e cartas dos imigrantes. A ideia do progresso que o imigrante trazia ao derrubar e "vencer" a floresta estava bastante presente nos relatos. Foi apresentado um desmatamento "civilizador", e que serviu, entre outros fatores, principalmente para a criação de uma agricultura familiar. A modificação da paisagem natural pela ação humana teria ocorrido através de vários fatores, entre eles as queimadas e o extermínio de parte da flora natural do RS. Dessa forma, foi narrado o avanço dos colonos na Floresta Subtropical, e a relação dos imigrantes europeus com a natureza através das diferentes técnicas de exploração da terra que foram empregadas.

José Paulo Eckert pesquisou a exploração da erva mate, na região de Rio Pardo, ao longo do século XIX, partindo de diferentes propostas de projetos de extração da erva na Floresta Subtropical. Dos três projetos, destacaram-se os ervateiros, o naturalista francês Aimé Bonpland, e os empreendimentos, estatais e privados, dos imigrantes europeus. A relação dos ervateiros com a floresta era a que possuía um maior conhecimento desse ambiente, pois estavam mais familiarizados com a floresta e o processo de extração da erva mate. A relação de Bonpland com a floresta foi de estudo e pesquisa, buscava reconhecer e analisar as espécies da flora e da fauna, bem como o desenvolvimento do extrativismo da erva mate e o seu processo, o que teria possibilitado compreender qual a infraestrutura seria 
a mais adequada para esta prática. Já a relação dos imigrantes europeus recém chegados com a floresta teria sido a de devastação. A queima e o extermínio de parte da flora e da fauna para o assentamento foi um elemento necessário para os imigrantes, sendo assim, não teriam participaram do extrativismo da erva mate de forma efetiva, vindo no futuro a dedicar-se a outras formas de exploração da natureza no território gaúcho, como o extrativismo da madeira.

Esther Mayara Zamboni Rossi e Eunice Sueli Nodari, em artigo seguinte, escrevem sobre o o processo de migração e a exploração do meio ambiente, no qual apontaram a transformação da paisagem natural pela ação humana. Essas transformações da paisagem remetem à ocupação indígena no território dos Campos de Cima da Serra, e em outros elementos, ao tropeirismo. Foram analisadas a região do Bioma Mata Atlântica e a modificação da paisagem, primeiramente pelos indígenas, mas, posteriormente e de forma mais radical, pelo processo imigratório europeu. Foi somente após a chegada dos imigrantes, em meados do século XIX, que a indústria madeireira teria apresentado um significativo crescimento, e a paisagem passou a ganhar uma ressignificação devido aos impactos das modificações ocasionadas pela formação e desenvolvimento das colônias. A construção das estradas e ferrovias, sob o discurso do progresso, favoreceu a valorização da indústria de exploração da madeira. Esse desmatamento teria trazido consequências à paisagem natural; uma vez que as Florestas de Araucária foram amplamente exploradas com a criação das companhias madeireiras.

No último artigo da segunda parte do livro, de Elenita Malta Pereira, foi abordada a luta dos citricultores, com a ajuda de José Lutzenberger, contrário a campanha da CANECC contra a proliferação do "cancro cítrico" - bactéria que ataca as plantações cítricas. Sob a ótica da CANECC, um efetivo resultado contra o avanço da bactéria seria o extermínio das plantações. Compreendeu-se duas vias no discurso referente a proliferação da bactéria: a de Lutzenberger e os representantes dos agricultores, que buscavam a preservação dos pomares não infectados, em contra partida aos órgãos oficiais da agricultura e determinados agrônomos que buscavam a erradicação de todas as plantas. Os debates em torno do tema foram mapeados, principalmente, pelos discursos encontrados nos jornais que apontavam as discordâncias entre ambas as partes. A militância de Lutzenberger, inclusive com um processo judicial pela preservação e indenização dos agricultores que tiveram suas safras arrancadas arbitrariamente, foi um significativo avanço das discussões na época. Os posicionamentos divergentes de Lutzenberger e dos irmãos Osvaldo e Miguel Porto, publicados no Jornal Zero Hora, apresentam um caminho sobre as questões ambientais do Rio Grande do Sul, principalmente em um período recente pós-ditadura, denunciando os órgãos do governo e sua forma de lidar com os problemas inerentes da proliferação da bactéria. No desfecho desse caso, em muito colaborou a decisão judicial a favor de um agricultor em manter sua safra, para que o posicionamento de Lutzenberger atingisse os demais agricultores, os quais passaram a resistir ao extermínio de suas plantações. Como resultado, também criaram-se Cooperativas para proteção e ajuda dos citricultores.

Na terceira e última parte, foram abordados temas referentes à Arqueologia e aos viajantes. No primeiro artigo, de Natalia Devitte, Neli Teresinha Galarce Machado e André Jasper, tratou-se dos descartes de resíduos, entre os séculos XIX e XX, no Vale do Taquari. Foi apontada a importância deste estudo para compreensão da relação do homem com o meio ambiente, bem como a forma que esses descartes podem ter alterado o ambiente natural, respingando até os dias de hoje. As práticas de descarte de lixo foram analisadas tal qual a forma que esses descartes são passíveis de narrar uma história do cotidiano através das análises dos artefatos arqueológicos. Os resíduos têm duas finalidades, uma 
para o Arqueólogo e outra para a História Ambiental. Observou-se que essas questões estavam relacionadas ao aumento do consumo em uma sociedade marcadamente capitalista. O manejo do lixo trilha por vias sociais, ambientais, culturais, espaciais e de questões de saúde, tendo sido significativo o impacto desse descarte naquela região. A investigação das lixeiras domésticas no Vale do Taquari apresentou dois roteiros de investigação, o depósito de refugos e as áreas de descarte. Para além do impacto ambiental, foi traçado um caminho sobre as práticas sociais e cotidianas.

O penúltimo artigo, de Fernanda Scneider, Sidnei Wolf, Marcos Rogério Kreutz e Neli Teresinha Galarce Machado, tratou igualmente do Vale do Taquari, embora abordando as questões relacionadas à ocupação humana pré-colonial nesse território, aliados a transformação da paisagem, e tendo como fio norteador a escolha do território devido as necessidades humanas versus o que o território poderia oferecer em termos de recurso naturais. A predominância da ocupação no Vale do Taquari, em áreas de altas altitudes com a vegetação de Florestas de Araucárias, poderiam ser decorrentes da abundância de pinhão na região. Muito da flora brasileira teria sido removida e/ou passado por um processo de transformação ambiental oriunda da ação humana para práticas de assentamento e agricultura. Outro fator que teria favorecido as modificações ecológicas pode ser observado através do cultivo de plantas domésticas em distintos locais no Sul do país. Contudo, a abertura de diversos caminhos na mata alterou a paisagem verde do Vale do Taquari, ocorrendo uma apropriação social da paisagem pelos povos indígenas - que transformaram o ambiente natural e reordenaram o cenário para seu assentamento, prática agrícola e abertura de trilhas e caminhos, que foram verificados através das análises e pesquisas arqueológicas na região.

O último artigo, de Dilson Peixoto e Taciane de Moraes, utiliza-se dos relatos de viajantes para compreender a exploração do ambiente natural, no Rio Grande do Sul, realizada pelos europeus, no período colonial, através da ótica dos diários de três viajantes do século XIX: John Luccock, Nicolau Dreys e Auguste Prouvansal de Saint- Hilaire. A pecuária e a agricultura foram os primeiros recursos utilizados pelos imigrantes europeus. Foram encontrados nos relatos dos viajantes, uma abundância e grande variedade no cultivo de frutas, verduras e legumes, no Rio Grande do Sul, e em menor proporção foi citada a extração de minério. Associou-se o crescimento urbano, em Porto Alegre, à existência de olarias e à extração de madeira, e outros recursos naturais para as construções urbanas. Encontrou-se nos relatos dos viajantes a utilização da fauna para a alimentação, pois, além da caça dos animais, utilizavam os produtos que eles produziam, como ovos, leites e peles. Os recursos naturais do Rio Grande do Sul foram vastamente empregados e apropriados pelos imigrantes europeus, que necessitavam deste meio para sua subsistência, e também para gerar uma pequena economia interna com a circulação de mercadorias e excedentes.

História ambiental no Rio Grande do Sul aborda as ações humanas, sejam individuais ou coletivas, bem como o percorrer político do ambientalismo, e a memória do Rio grande do Sul, por meio de um abrangente panorama que tem como ponto em comum a História Ambiental, mas que não se resume äpenas a ela. Aponta as diferentes memórias sobre o Lago Guaíba e o Rio dos Sinos, lança um novo olhar sobre os relatos dos viajantes e sobre os artefatos encontrados; aborda a memória da imigração e o legado da alteração da paisagem pela ação humana, bem como a memória biográfica de personalidades engajadas no ambientalismo. A iniciativa do Grupo de Trabalho de História Ambiental da Associação Nacional de História - ANPUH-Rio Grande do Sul traz uma significativa contribuição para a História Ambiental do Rio Grande do Sul, apresentando um quadro 
sobre como tem se desenrolado as relações humanas e tensões sociais presentes no ambiente natural do Estado, contribuindo, assim, para um debate crítico acerca desse tema. 